The Influence of

\title{
Metal Ion Concentrations and pH Value on the Growth of a Nitrosomonas Strain Isolated from Activated Sludge
}

\author{
By J. E. LOVELESS AND H. A. PAINTER \\ Water Pollution Research Laboratory, Stevenage, Hertfordshire
}

(Accepted for publication 3I October 1967)

\begin{abstract}
SUMMARY
A strain of Nitrosomonas europaea was isolated from activated-sludge effluent by a dilution method which readily demonstrated the presence of contaminating heterotrophs and yielded a high proportion of tubes containing pure cultures of ammonia-oxidizing bacteria. Copper, sodium, calcium and magnesium stimulated growth of pure cultures, and effects of deficiencies of these metals were demonstrated. Ethylenediaminetetra-acetic acid improved growth in the basal medium, and abolished the toxic effect of added copper; it was, however, inhibitory at low calcium concentrations. The effect of $\mathrm{pH}$ value on the growth of $N$. europaea appeared to be dependent on the metal ion content of the medium although the optimum $\mathrm{pH}$ value was always between 7.5 and 8 . The growth rate constant in pure culture was similar to that previously observed for nitrification in Thames water, but double that previously observed for nitrification of sewage by activated sludge. The Michaelis constants for ammonia and oxygen were similar to those found for nitrification in activated sludge.
\end{abstract}

\section{INTRODUCTION}

In his review of the metabolism of chemolithotropic bacteria, Lees (I960) indicated that the recalcitrant nature of this group of organisms was the reason for the relatively slow progress being made in elucidating the biochemical problems they present. Nitrosomonas, which uses carbon dioxide to oxidize ammonia to nitrite, is typical of this group. The most useful recent advances in growing Nitrosomonas in pure culture were made by Engel \& Alexander (1958) when they introduced a precipitate-free medium, and by Skinner \& Walker (I96I) who used this medium in a continuous-culture apparatus. Skinner \& Walker reported that, when the population of Nitrosomonas exceeded about $3 \times 10^{8}$ organisms $/ \mathrm{ml}$., the growth rate decreased; this was attributed to inadequate aeration. Gundersen (1957) was unable to maintain strains of Nitrosomonas for more than a year.

In the present work, it was originally intended to develop a culture system which would provide large-scale batch cultures for biochemical investigations, and also background information for the continuous culture of large numbers of organisms for survival and inoculation studies in model sewage-purification systems. The kinetics of nitrification in these systems have been interpreted by the application of electronic computation to hypothetical changes in the proportions of Nitrosomonas in the mixed populations of micro-organisms which are the agents of purification (Downing,

Vol. 5I, No. 3 was issued 28 May 1968 
Painter \& Knowles, I964; Knowles, Downing \& Barrett, 1965). However, it became quite clear from early experiments that none of the media hitherto used was entirely satisfactory. It seems likely that essential trace elements have commonly arisen fortuitously as contaminants of water, chemicals and glassware. It would also appear that under certain conditions growth rates can be dramatically decreased by traces of toxic ions arising from similar sources. The main theme of the present work thus became an attempt to define more closely some of the conditions necessary for growth. Much still remains to be done along these lines before consistently good growth can be obtained.

The isolation of the organism has also remained a tedious and haphazard process. Van Niel (1954), in reviewing autotrophic bacteria, suggested that the isolation of Nitrosomonas was in itself an accomplishment worthy of publication. Further progress towards a satisfactory technique for the isolation in pure culture was made by Lewis \& Pramer (1958), when they combined the precipitate-free medium of Engel \& Alexander (1958) with a dilution technique. It is one of the objectives of this paper to indicate further improvements in this isolation technique and specify more closely the conditions necessary for success.

\section{METHODS}

Apparatus. A satisfactory pH-controlled and sterilizable batch culture unit was designed after referring to the work of Skinner \& Walker (I96I), Engel \& Alexander (1958) and Callow \& Pirt (1956). The output stage of a pH meter was connected in series with a relay unit (Transitrol, Ether Ltd., Stevenage) which operated an electromagnetic valve controlling the entry of alkali to the culture vessel. The calomel electrode was immersed in saturated potassium chloride in a separate bottle, and electrical contact with the medium in the culture vessel was maintained by a bridge filled with $2 \%$ agar containing potassium chloride, and ending in a sintered glass plug immersed in the culture medium. The glass electrode was sterilized by soaking overnight in $0 . \mathrm{I} \mathrm{M}$-hydrochloric acid or soaking for $\mathrm{I} \mathrm{hr}$ in a I \% (w/v) solution of $\beta$-propiolactone (Taplin, 1962) before being inserted aseptically into the freshly sterilized medium cooled to below $50^{\circ}$. Instability in the $\mathrm{pH}$ reading was traced to static charges on various parts of the apparatus but was overcome by adequate earthing; in extreme situations even the cases of the $\mathrm{pH}$ meters, the potassium chloride reservoir and the medium had to be earthed.

The culture vessel was a Io 1 . aspirator, and aeration was by means of a porous porcelain candle connected to an airline and fitted in a silicone-rubber bung in the lower opening; this bung also held a sampling tube fitted with a shielding hood and the agar bridge from the calomel electrode. The neck of the aspirator was closed with a cotton-wool plug wrapped in cellophan to prevent wetting by the spray thrown up during aeration. Glass tubes inserted in the plug served to introduce the inoculum and the sterilized glass electrode. The alkali used for neutralizing the nitrous acid produced during growth was usually supplied as approximately $3 \mathrm{~N}$-ammonium carbonate, but in some earlier experiments ammonium hydroxide was tried, with and without the addition of sodium carbonate.

Aeration of cultures. From the known rate of flow of air to the cultures and from their measured respiration rate, it was calculated that sufficient air was supplied at all times. This was occasionally confirmed by determining the concentration of dissolved oxygen by means of the dropping-mercury or the Mackereth electrode (Painter \& 
Jones, 1963; Briggs \& Viney, 1964). At no time was the concentration below $2 \mathrm{mg}$. $\mathrm{O}_{2} / 1$., and since this value is well above the Michaelis constant (see Results) it was concluded that oxygen was not limiting growth.

Some cultures were grown in screw-capped bottles, in which no direct determinations of the concentration of dissolved oxygen were made. Initially the medium was saturated with respect to oxygen. During incubation samples were withdrawn, no further liquid was added and the bottles were shaken, thereby introducing further oxygen. The values for doubling times observed in these cultures were about the same as those obtained in the large vessels, suggesting that oxygen supply was satisfactory.

Media. The media used were developed from the suspension-free medium described by Skinner \& Walker (I96I). Sodium was found to stimulate growth. It was also found that the substantial $\mathrm{pH}$ change which occurred on autoclaving some media was due to loss of ammonia. This hazard was largely eliminated by decreasing the concentration of ammonia-nitrogen and substituting ammonium carbonate for ammonium sulphate. The final medium contained $36 \mathrm{mg}$. $\mathrm{Na}$ (as $\mathrm{Na}_{2} \mathrm{SO}_{4} \cdot 10 \mathrm{H}_{2} \mathrm{O}$ ), I $5 \mathrm{mg}$. Ca (as $\mathrm{CaCl}_{2}$ ), Io mg. $\mathrm{Mg}$ (as $\mathrm{MgSO}_{4} \cdot 7 \mathrm{H}_{2} \mathrm{O}$ ), $32 \mathrm{mg}$. $\mathrm{P}$ (as $\mathrm{KH}_{2} \mathrm{PO}_{4}$ ), and $0.2 \mathrm{mg}$. Fe (chelated) per litre, dissolved in de-ionized distilled water. The chelated iron was added by diluting $\mathrm{I} \mathrm{ml}$. of a solution of $0.48 \% \mathrm{FeCl}_{3} .6 \mathrm{H}_{2} \mathrm{O}, 0.3 \mathrm{I} 2 \% \mathrm{NaCl}$ and $0.643 \%$ 'Chel 138' (Geigy Chemical Co., New York; ethylene diamine di(o-hydroxyphenyl) acetic acid) to I 1 . of medium (Engel \& Alexander, 1958). For the isolation, $100 \mathrm{mg}$. yeast extract/1. was added so that heterotrophs became evident after 2-3 days of incubation. In the $\mathrm{pH}$-controlled batch and enrichment cultures, the $\mathrm{pH}$ value was maintained at the predetermined value with ammonium carbonate, which also provided nitrogen and supplemented the supply of carbon dioxide from the atmosphere. In medium prepared for small volume experiments in bottles and flasks, nitrogen was added as ammonium bicarbonate at a concentration of $20 \mathrm{mg}$. N/l. and final adjustments of $\mathrm{pH}$ value were made with dilute sodium hydroxide. This medium was augmented for making isolations with I00 $\mathrm{mg}$. Difco yeast extract/1., the $\mathrm{pH}$ value being adjusted to $7 \cdot 9$; it was then dispensed in test-tubes in convenient volumes and sterilized in a domestic pressure cooker for $10 \mathrm{~min}$. at $\mathrm{I} 2 \mathrm{I}^{\circ}$. In experiments done in $\mathrm{I}$ oz. screwcapped bottles, improved $\mathrm{pH}$ control was achieved by adjusting $\mathrm{pH}$ values up to $7 \cdot 9$ with sodium bicarbonate; for any further increase in alkalinity sodium hydroxide was used. The bottles were filled to the brim at the beginning of experiments and the caps were screwed on tightly to minimize the loss of volatile components from the liquid phase. All additions, including the inocula, were made to the largest practicable volumes of the medium before dispensing into smaller lots. The size of the inocula was usually I $-2.5 \mathrm{ml} . / 1$. medium so that the concentration of nitrite carried over was below $0 \cdot 1 \mathrm{mg} . \mathrm{N} / 1$.

Source and isolation of organism. Preliminary experiments on the effects of $\mathrm{Na}_{2} \mathrm{SO}_{4}$ on growth were made with a pure culture of Nitrosomonas given to us by Dr N. Walker (Rothamsted Experimental Station, Harpenden, Hertfordshire) and originally isolated by Dr H. L. Jensen (Lyngby, Denmark), but this culture was lost at an early stage and most of our work was therefore done with a strain isolated from the effluent from an activated-sludge plant. This isolation was made from an enriched culture inoculated with $10 \mathrm{ml}$. of effluent in 91 . of the mineral salt medium and allowed to grow in the $\mathrm{pH}$-controlled apparatus to a population density equivalent to 500-1000 $\mathrm{mg}$. 
nitrite-N/1. While still in the exponential growth phase, dilutions of this culture were made in isolation medium to a concentration of about 2 bacteria/ml., based on a rough count using a haemocytometer (Skinner \& Walker, 196I); volumes (0.5 ml.) of this suspension were distributed aseptically into test-tubes of sterile isolation medium and incubated at $27^{\circ}$ for II-I4 days before sampling for nitrite.

Preparation of glassware. Flasks and bottles were prepared by washing in 'HaemoSol', a buffered alkaline detergent (manufactured by Meineke and Co.), rinsing several times in tap water and twice in distilled water. They were finally filled with deionized water and autoclaved for $\mathrm{I} \mathrm{hr}$ at $\mathrm{I} 2 \mathrm{I}^{\circ}$.

Nitrite was determined by the modified Griess-Ilosvay diazotization method due to Montgomery \& Dymock (I96I).

Estimation of growth. Throughout the present work the concentration of nitrite produced has been used as the main criterion of bacterial growth, because the greater sensitivity, simplicity and accuracy of the method of determination of this compound make it a better choice than the estimation of cell carbon, mass or numbers. Nitrite production is a true measure of growth of Nitrosomonas, at least up to $500 \mathrm{mg}$. N/1., as shown by Buswell, Shiota, Lawrence \& Van Meter (1954), and by Engel \& Alexander (I958). As mentioned earlier ('Aeration of cultures'), the concentration of nitrite in screw-capped bottle cultures increased logarithmically with time but the growth rate was not always determined; instead, in some experiments the results are expressed as concentration of nitrite after a stated period of incubation. It was valid to compare these concentrations in a single experiment since the inoculum was the same for all vessels; but the comparison could not be made between experiments since the activity of the inocula varied from experiment to experiment.

\section{RESULTS}

\section{Isolation of pure strains}

A high success rate was achieved by the method described. Seven out of nine experiments intended to isolate or re-isolate the organism were successful, the number of pure isolates obtained in 14 days varying between $5 \%$ and $70 \%$ of the tubes inoculated in each experiment, whereas previously, when using the unmodified medium and unenriched seeds, isolates were not obtained even after $2 \mathrm{I}$ days. Confirmation of purity was obtained by finding no growth in nutrient broth and no evidence of contaminating organisms on microscopical examination.

The pure strain chosen for growth experiments was very motile; the bacteria were somewhat elliptical in shape and measured about $\mathrm{I}-\mathrm{I} \cdot 25 \mu$ in diameter. The bacteria were well-dispersed and motile in the early stages of a culture; later a substantial flocculent deposit usually became apparent and within flocs micro-colonies of a few dozen organisms could often be seen. The characters of the organism isolated fit the description for Nitrosomonas europaea in Bergey's Manual (1957).

\section{Reproducibility of growth of the stock strain in pure culture}

In the first $\mathrm{pH}$-controlled batch cultures, exponential growth at a constant, though low, rate (doubling time $48 \mathrm{hr}$ ) was achieved up to nitrite concentrations of $2500 \mathrm{mg}$. $\mathrm{N} / 1$. (equivalent to $96 \mathrm{mg}$. organic C/1.) (curve A, Fig. I), which is much higher than any other reported. Lower maximum concentrations of nitrite were obtained in the 
next group of experiments, and it appeared, surprisingly, that when more care was taken in preparing glassware and in selecting reagents, it became more difficult to achieve high yields.

To test the possibility that there had been a mutation in the stock strain, its growth curve was compared with simultaneous growth curves of cultures in the same medium inoculated with I ml./l. of water from an unpolluted river or of clear supernatant fluid from an aqueous suspension of soil. In all these cultures, both the final nitrite production and the doubling time were nearly the same, indicating that the falling-off in growth was due to the influence of the medium and not to genetic change in the stock strain.

To test the reproducibility of results within one experiment, six batch cultures were grown under identical conditions; the results of plotting the logarithm of nitrite concentration against time are shown in Fig. I (curves B, C). Consistent results were obtained, particularly for five of the vessels, doubling times in the initial stages varying from 19.2 to $2 \mathrm{I} \mathrm{hr}$. The decline in the rate of growth in the later stages was typical of the results usually obtained in the present work.

Reproducibility in experiments in screw-capped bottles was not so good as in the large batch cultures. However, it was possible to set up many more parallel cultures in each experiment to enhance the reliability of the mean obtained. Some of the inconsistency was found to be due to a 'glassware factor' and many experiments were made with a variety of vessels, types of glass and washing procedures in order to determine the best way of diminishing this source of error. Although these experiments were complicated to some extent by $\mathrm{pH}$ changes, caused by loss of $\mathrm{NH}_{3}$ and $\mathrm{CO}_{2}$ from vessels where the closures were not effective, it became clear that variations between replicates could be substantially decreased by following the strict washing procedure already described.

\section{Source of water for making media}

Originally media were prepared with distilled water from a high-rate still lined with tinned Admiralty metal (containing tin, copper and antimony). Analysis of this water after cultural difficulties had become serious revealed variable concentrations of copper within the range $0.05-0.08 \mathrm{mg} . / 1$. and zinc within the range $0.05-0 . \mathrm{I} \mathrm{mg} . / 1$; analysis was also made for antimony but none was detected. A measure of the toxicity of this 'crude' distilled water is shown in Fig. 2, in which growth on medium prepared from it is compared with that on media prepared from (I) water twice-distilled in an all-glass apparatus, (2) demineralized distilled water (using 'Bio-deminrolit', The Permutit Co. Ltd.), and (3) 'crude' distilled water containing $5 \mathrm{mg}$./1. ethylenediaminetetraacetic acid disodium salt (EDTA). The toxic nature of the 'crude' distilled water is clearly demonstrated and the improved growth in the presence of EDTA suggests that metals are responsible.

\section{Effect of $p H$ value on growth}

In experiments to determine the effect of $\mathrm{pH}$ value on growth rate, daily measurements of the concentration of nitrite were made in samples from each of six cultures controlled at different $\mathrm{pH}$ values; in Fig. 3 the results of two such experiments have been expressed by plotting the mean doubling time against $\mathrm{pH}$ value. In the first of these experiments, 'crude' distilled water was used and the curve obtained had a fairly 
sharp trough at about $\mathrm{pH} 7 \cdot 8$; this contrasted with the relatively flat curve obtained with demineralized water over the $\mathrm{pH}$ range $7-8 \cdot 2$. These results suggest that the effect of $\mathrm{pH}$ value on growth rate is different at different concentrations of heavy metal ions, and vice versa. Working with small cultures in screw-capped bottles, the effect of $\mathrm{pH}$ value was determined at different concentrations of added copper. Although an interrelationship between the concentration of the element and $\mathrm{pH}$ value was demonstrated, the effect was not as great as would be expected from the results in Fig. 3 . Several metal ions were tested individually over a range of concentrations for evidence of biological activity at $\mathrm{pH} 7 \cdot 3$ and $7 \cdot 9$. In Table $\mathrm{I}$ are summarized the results of

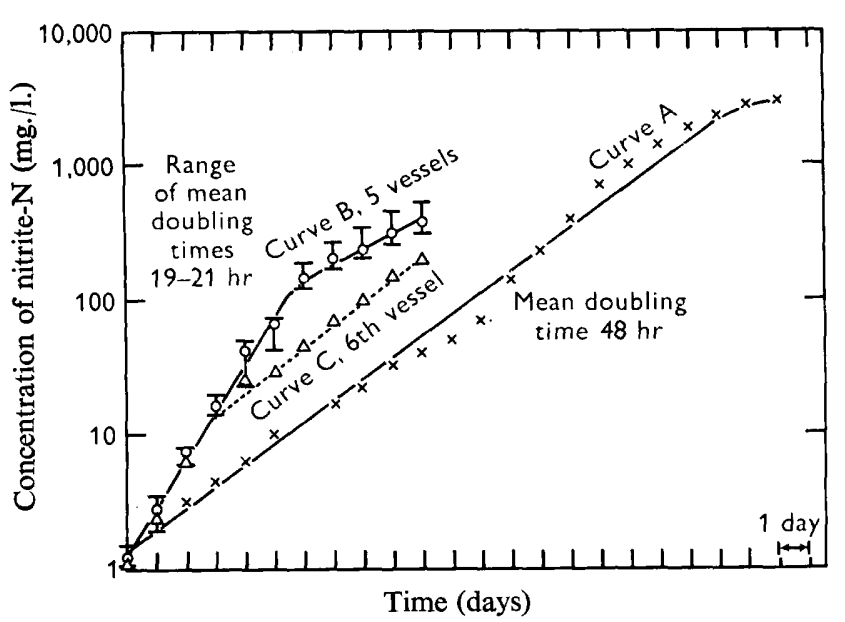

Fig. I

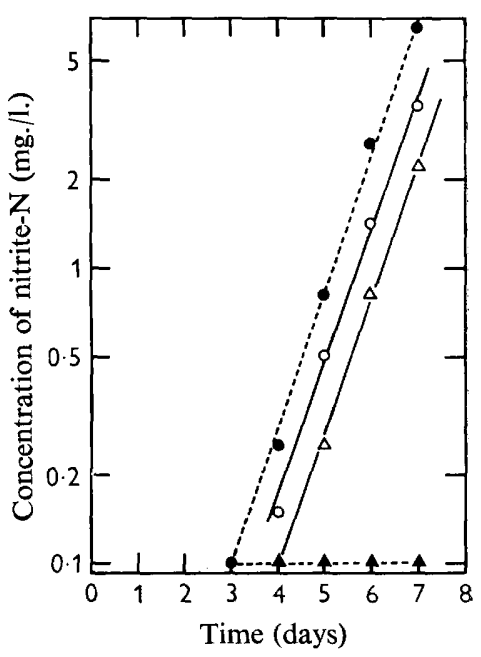

Fig. 2

Fig. I. Exponential growth curves of Nitrosomonas europaea in $\mathrm{pH}$-controlled batch culture. $\bigcirc-O$, Mean of 5 replicates; $\triangle . .-\triangle$, 6th replicate; $\times \_-\times$, exponential growth to a high concentration of nitrite (single vessel). Vertical lines indicate range.

Fig. 2. Effects of various treatments of distilled water on growth rate of Nitrosomonas in small bottles. -... $\triangle-\triangle$, 'crude' distilled water with EDTA (5 mg./1.); $\Delta \ldots . . . \Delta$, 'crude' distilled water. Each point is an average of 6 determinations.

Table I. Summary of the effect of various metals on growth of Nitrosomonas

\begin{tabular}{|c|c|c|c|}
\hline \multirow[b]{2}{*}{ Element } & \multirow[b]{2}{*}{$\begin{array}{l}\text { Range tested } \\
\text { (mg./1.) }\end{array}$} & \multicolumn{2}{|c|}{$\begin{array}{c}\text { Concentration at which effect } \\
\text { observed (mg./l.) }\end{array}$} \\
\hline & & Stimulation & Inhibition \\
\hline $\mathrm{Cu}$ & $0.005-0.56$ & $0.005-0.03$ & $0.05-0.56$ \\
\hline $\mathrm{Cu}^{*}$ & $0.005-0.48$ & None & None \\
\hline $\mathrm{Ca}$ & $0.5-20$ & None & None \\
\hline $\mathrm{Ca}^{*}$ & $0.5-20$ & $0.5-10$ & None \\
\hline $\mathrm{Mg}$ & $12 \cdot 5-100$ & $12 \cdot 5-50$ & $50-100$ \\
\hline $\mathrm{Zn}$ & $0.005-0.5$ & None & $0.08-0.5$ \\
\hline Co & $0.005-0.5$ & None & $0.08-0.5$ \\
\hline $\mathrm{Al}$ & $0.005-1 \cdot 0$ & None & None \\
\hline $\mathrm{Sr}$ & $0.005-0.05$ & None & None \\
\hline $\mathrm{Pb}$ & $0.005-0.05$ & None & None \\
\hline B & $0.005-0.05$ & None & None \\
\hline
\end{tabular}

* In presence of $5 \mathrm{mg}$./1. EDTA. 
these screening tests and of other more detailed tests on those metals which showed biological activity. The effect of five concentrations of calcium $(0.5-20 \mathrm{mg}$./1.) at five $\mathrm{pH}$ values ( $\mathrm{pH} \mathrm{6.9-8.5)}$ was determined in the absence and presence of $5 \mathrm{mg}$. EDTA Il. The calculated value of calcium carried over with the inoculum was about $0.05 \mathrm{mg} .1$. There was little difference in the concentrations of nitrite reached in the presence of the five different concentrations of added calcium at any $\mathrm{pH}$ value; the mean values are given in Table 2. In the absence of EDTA there was little difference between the values obtained with or without added calcium. However, in the presence of $5 \mathrm{mg}$. EDTA $\mathrm{I}$ l. growth was depressed in the absence of added calcium while at $\mathrm{pH} 7 \cdot 3$ and above in the presence of added calcium the nitrite values reached were substantially higher than in the absence of EDTA.

Table 2. Effect of calcium, in presence and absence of EDTA, and of magnesium on growth of Nitrosomonas in small bottles

Nitrate formation was taken as proportional to growth yield

\begin{tabular}{|c|c|c|c|c|c|c|}
\hline \multirow[b]{4}{*}{$\begin{array}{l}\mathrm{pH} \text { of } \\
\text { medium }\end{array}$} & \multicolumn{6}{|c|}{ Average concentration of nitrite after 6 days incubation (mg. N/1.) } \\
\hline & \multicolumn{4}{|c|}{ Concentration of calcium added (mg./l.) } & \multirow{2}{*}{\multicolumn{2}{|c|}{$\begin{array}{l}\text { Concentration of } \\
\text { magnesium added } \\
\text { (mg./l.) }\end{array}$}} \\
\hline & \multicolumn{2}{|c|}{ No EDTA added } & \multicolumn{2}{|c|}{$5 \mathrm{mg}$. EDTA/l. added } & & \\
\hline & $\begin{array}{c}\circ \\
(15)\end{array}$ & $\begin{array}{c}0.5-20 \\
(60)\end{array}$ & $\begin{array}{c}0 \\
\text { (I5) }\end{array}$ & $\begin{array}{c}0.5-20 \\
(60)\end{array}$ & $\begin{array}{c}0 \\
(I 5)\end{array}$ & $\begin{array}{c}12 \cdot 5-100 \\
(60)\end{array}$ \\
\hline $6 \cdot 9$ & $3 \cdot 0$ & 3.5 & $2 \cdot 0$ & $\mathbf{I} \cdot \mathbf{2}$ & 0.1 & $2 \cdot 0$ \\
\hline $7 \cdot 3$ & $4 \cdot 5$ & $5 \cdot 0$ & $\mathbf{I} \cdot \mathbf{O}$ & 4.0 & $0 \cdot \mathbf{I}$ & $2 \cdot 2$ \\
\hline $7 \cdot 7$ & $5 \cdot 0$ & 4.0 & $2 \cdot 0$ & $5 \cdot 0$ & $2 \cdot 0$ & $4 \cdot 0$ \\
\hline $8 \cdot 3$ & $5 \cdot 5$ & $6 \cdot 0$ & 3.5 & $9 \cdot 0$ & $5 \cdot 0$ & $6 \cdot 0$ \\
\hline $8 \cdot 5$ & 6.0 & $6 \cdot 5$ & $3 \cdot 7$ & $9 \cdot 0$ & $6 \cdot 5$ & $6 \cdot 0$ \\
\hline
\end{tabular}

Figures in parentheses are numbers of determinations.

Table 3. Effect of copper in the presence and absence of EDTA on growth of Nitrosomonas in small bottles

\begin{tabular}{|c|c|c|}
\hline \multirow{2}{*}{$\begin{array}{l}\text { Concentration } \\
\text { of } \\
\text { copper added } \\
\text { (mg./1.) }\end{array}$} & \multicolumn{2}{|c|}{$\begin{array}{l}\text { Concentration of nitrite after } \\
\text { I I days incubation (mg. N/1.) } \\
\text { (average of I } 5 \text { determinations) }\end{array}$} \\
\hline & No EDTA & $5 \mathrm{mg} . \mathrm{EDTA} / 1$ \\
\hline 0 & 0.25 & $5 \cdot 3$ \\
\hline 0.005 & $I \cdot O$ & $4 \cdot 5$ \\
\hline 0.02 & $2 \cdot 3$ & $6 \cdot I$ \\
\hline 0.04 & $2 \cdot 4$ & $6 \cdot 4$ \\
\hline 0.06 & $2 \cdot 8$ & $6 \cdot 4$ \\
\hline 0.48 & 0.25 & 6.0 \\
\hline
\end{tabular}

The effect of adding magnesium within the range $12 \cdot 5-100 \mathrm{mg}$./1. (background concentration about $0.02 \mathrm{mg}$. 1 .) was tested at five different $\mathrm{pH}$ values; apart from a slight decrease in growth rate at high values magnesium appeared to have very little effect. However, as shown in Table 2, the effect of deficiency of magnesium was far more marked at the low $\mathrm{pH}$ values than at high.

Copper was also tested for its effect on growth, both in the absence and presence of $5 \mathrm{mg}$. EDTA/1. Table 3 contains the mean values for nitrite production at five different $\mathrm{pH}$ values. Increasing stimulation by copper was found up to an added amount 
of $0.02 \mathrm{mg}$. $/ \mathrm{l}$. with a levelling off up to about $0.06 \mathrm{mg} . / 1$; at an added concentration of $0.48 \mathrm{mg}$. $/ 1$. the stimulating effect of copper had disappeared. The stimulation by copper was reproducible, since of ten experiments nine showed enhanced growth in its presence $(0.03 \mathrm{mg}$./1.) over controls with no added copper. The results of these experiments when compared with those of similar experiments in which EDTA had been added are interesting. Not only did EDTA increase the tolerance to high concentrations of copper, but it also improved the growth at all concentrations of copper tested (Table 3) and was advantageous at most $\mathrm{pH}$ values (Fig. 4). This was in contrast to the growth-depressing effect observed at threshold concentrations of calcium (Table 2).

Zinc and cobalt were the only other metals tested which showed any biological activity. Toxicity was fairly marked with both these metals at $0.5 \mathrm{mg} . / 1$. in the presence of $0.03 \mathrm{mg} . \mathrm{Cu} / \mathrm{l}$.

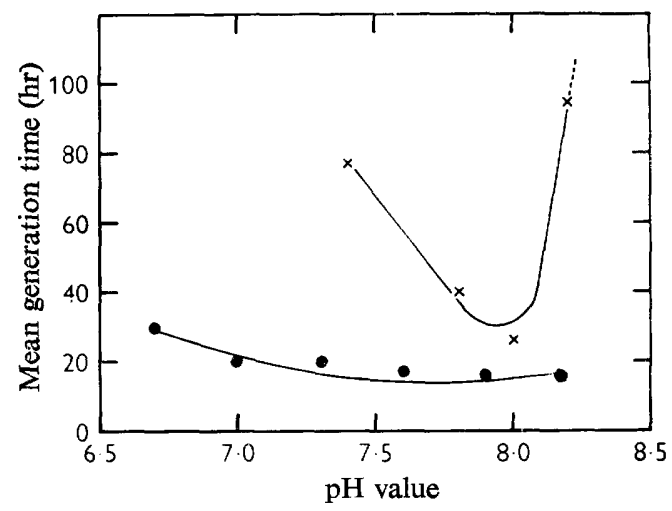

Fig. 3

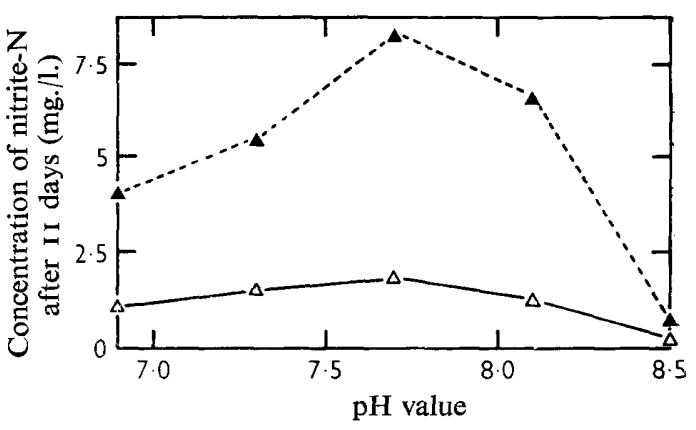

Fig. 4

Fig. 3. Dependence of mean generation time of Nitrosomonas on $\mathrm{pH}$ value of medium. Generation time measured by changes in nitrite concentration in $\mathrm{pH}$-controlled batch cultures. $\times \longrightarrow \times$, Distilled water; $\longrightarrow$, demineralized water.

Fig. 4. Effect of EDTA at various $\mathrm{pH}$ values on growth of Nitrosomonas in small bottles. $\Delta . . \Delta$, With EDTA $(5 \mathrm{mg} . / 1.) ; \triangle \longrightarrow \triangle$, no EDTA. Each point is the average of three determinations.

\section{Effect of sodium}

When studying Nitrosomonas, it has been standard practice to use ammonium sulphate as a source of ammonia, and to neutralize the nitrous acid produced with sodium bicarbonate; this often resulted in the accumulation of high concentrations of sodium and sulphate ions. For example, in the cultures of Skinner \& Walker (I96I) sodium appears to have reached a concentration of about $0.4 \%$ and sulphate ions about $0.5 \%$.

In Fig. 5 the effect of various concentrations of sodium sulphate on the doubling time of the Jensen strain in small bottles is shown. A marked stimulation was obtained at sodium $0.06-0.15 \%$, with inhibition at $0.7 \%$. In other experiments stimulatory effects were observed with similar concentrations of sodium added, either as sulphate or chloride (Fig. 5), indicating that sodium rather than sulphate or chloride was involved. Marked stimulation of this and the activated-sludge strain by sodium also occurred, as evidenced by the doubling times calculated from data collected from $\mathrm{pH}$-controlled batch experiments (Table 4). 


\section{Growth-rate constant}

Values obtained in the present work for the growth-rate constant and the mean generation time of Nitrosomonas are presented in Table 4 together with values found by other workers. It can be seen that the Jensen strain grew at higher rates than did the isolate from activated sludge with which the shortest doubling-time obtained was I $6 \mathrm{hr}$. The stimulatory effects on growth of sodium, magnesium and EDTA are also illustrated.

Table 4. Summary of growth-rate constants of Nitrosomonas (batch culture)

\begin{tabular}{|c|c|c|c|c|c|}
\hline Investigation & Medium & $\begin{array}{c}\mathrm{pH} \\
\text { value }\end{array}$ & $\begin{array}{l}\text { Tempera- } \\
\text { ture } \\
\left({ }^{\circ}\right)\end{array}$ & $\begin{array}{l}\text { Growth- } \\
\text { rate } \\
\text { constant } \\
\left(\text { days }^{-1}\right)\end{array}$ & $\begin{array}{l}\text { Mean } \\
\text { genera- } \\
\text { tion } \\
\text { time } \\
\text { (hr) }\end{array}$ \\
\hline $\begin{array}{l}\text { Present work } \\
\text { Jensen strain }\end{array}$ & $\left.\begin{array}{l}\text { Complete* (distilled water) } \\
\text { Complete (distilled water) } \\
\text { Complete (distilled water) } \\
\text { Na omitted }\end{array}\right\}$ & $\begin{array}{l}8 \cdot 0 \\
7 \cdot 6 \\
8 \cdot 0 \\
8 \cdot 0\end{array}$ & $\begin{array}{l}25 \\
25 \\
25 \\
25\end{array}$ & $\begin{array}{l}1 \cdot 38 \\
0 \cdot 88 \\
0 \cdot 69 \\
0 \cdot 39\end{array}$ & $\begin{array}{l}12 \\
19 \\
24 \\
46\end{array}$ \\
\hline $\begin{array}{l}\text { Isolate from } \\
\text { effluent of } \\
\text { activated-sludge } \\
\text { process }\end{array}$ & $\left.\begin{array}{c}\text { Complete* (distilled water) } \\
\text { Complete (distilled water) } \\
\text { Na omitted }\end{array}\right\}$ & $\begin{array}{l}7 \cdot 6 \\
8 \cdot 0 \\
8 \cdot 0 \\
7 \cdot 9 \\
8 \cdot 0 \\
8 \cdot 0 \\
7 \cdot 8 \\
7 \cdot 8 \\
8 \cdot 0 \\
8 \cdot 0\end{array}$ & $\begin{array}{l}25 \\
25 \\
25 \\
25 \\
25 \\
25 \\
25 \\
25 \\
25 \\
25\end{array}$ & $\begin{array}{l}0.88 \\
0.69 \\
0.39 \\
1.03 \\
0.42 \\
0.69 \\
0.79 \\
0.57 \\
0.28 \\
0.83\end{array}$ & $\begin{array}{l}19 \\
24 \\
46 \\
16 \\
40 \\
24 \\
21 \\
29 \\
58 \\
20\end{array}$ \\
\hline Engel (I930) & Suspended solids present & $\sim 8.0$ & 30 & $I \cdot I 9$ & I4 \\
\hline Bömeke (I946) & Suspended solids present & $\sim 8 \cdot 0$ & 30 & $\mathrm{I} \cdot 03$ & 16 \\
\hline Lees (1952) & Suspended solids present & $\sim 8 \cdot 0$ & 30 & 0.46 & 36 \\
\hline Buswell et al. (1954) & BOD dilution water & $8-8 \cdot 5$ & $30,25,20$ & $\begin{array}{c}\mathrm{I} \cdot 74, \mathrm{I} \cdot 39 \\
0.94\end{array}$ & $\begin{array}{c}9 \cdot 5,12 \\
17 \cdot 5\end{array}$ \\
\hline $\begin{array}{l}\text { Engel \& } \\
\text { Alexander (1958) }\end{array}$ & Soluble & $8 \cdot 0$ & 25 & $1 \cdot 5$ & II \\
\hline Skinner \& Walker & Soluble & $7-7 \cdot 4$ & $28-32$ & $2 \cdot \mathrm{I}, \mathrm{I} \cdot 5 \mathrm{I} \dagger$ & $8, \mathrm{I} I-16 \dagger$ \\
\hline
\end{tabular}

Values linked with braces refer to simultaneous determinations.

* See text. † Continuous culture.

There was a substantial, unexplained, variation from experiment to experiment in the mean generation time of the activated-sludge isolate grown on the complete medium ( $16-58 \mathrm{hr}$ ), although, as has already been mentioned, good replication was obtained in simultaneous determinations.

The effect of temperature on growth is illustrated in Fig. 6, in which are plotted the average results of six parallel cultures at each of six different temperatures. Best growth and shortest lag time occurred at $30^{\circ}$. Comparison with data (Fig. 6) for a pure culture of an isolate from a percolating filter (Buswell et al. 1954), and with data for production of nitrite in activated sludge and in Thames water (Knowles et al. 1965), shows that the growth constant increased by roughly threefold from $10^{\circ}$ to $20^{\circ}$ and that above about $25^{\circ}$ the curves for both pure cultures began to deviate from the straight line while those for impure cultures did not. 


\section{Yield constant}

In a few of the $\mathrm{pH}$-controlled batch cultures the concentration of bacteria was determined by centrifuging, drying and weighing the deposit from a convenient volume. The 'yield constant' or 'economic coefficient' was calculated by dividing the concentration of bacteria by the concentration of nitrite nitrogen formed. The results showed a fairly wide variation between about 0.1 and 0.03 . It may be significant that the higher values were from the least concentrated cultures and therefore those most sensitive to error because of the presence of mineral precipitates. These values were, however, of the same order as those reported by other workers (see Downing et al. I964).

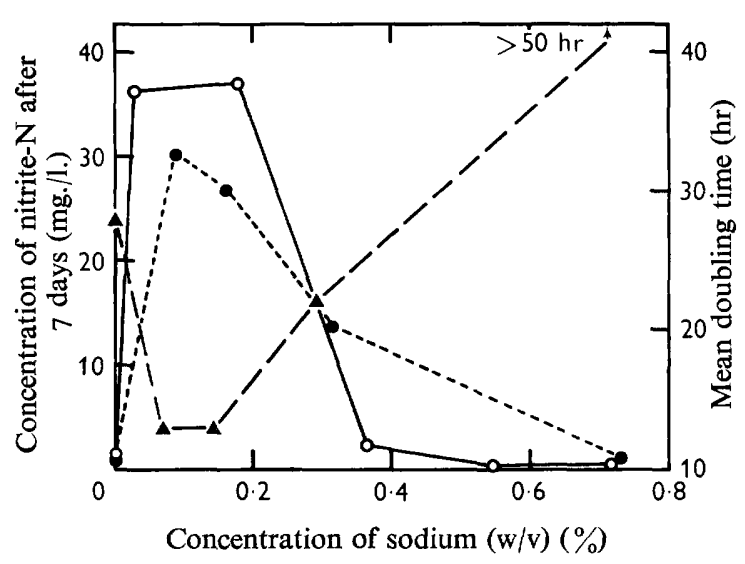

Fig. 5

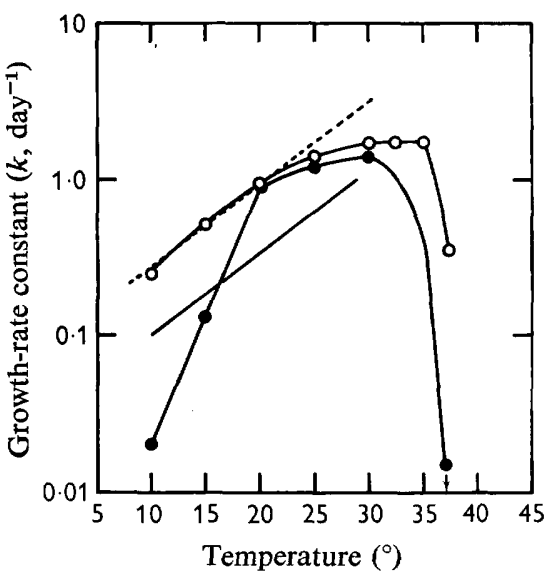

Fig. 6

Fig. 5. Effect of sodium salts on growth of Nitrosomonas (Jensen strain). Experiment I (in small bottles): $\bigcirc-O$, effect of sodium, as chloride, on nitrite production; effect of sodium, as sulphate, on nitrite production. Each point is the average of 4 determinations. Experiment 2 (in $\mathrm{pH}$ controlled large batch cultures): $\mathbf{\Delta}-\mathbf{\Delta}$, effect of sodium as sulphate on mean doubling time.

Fig. 6. Effect of temperature on growth rate of Nitrosomonas in pure culture compared with that in Thames water and activated sludge. -..-.-, Thames water (Knowles, Downing \& Barrett, 1965). - - Pure culture (from activated sludge-present work). $\bigcirc-0$, Pure culture (Buswell et al. 1954) —-, Activated sludge (Knowles et al. 1965).

\section{Michaelis constants}

We were unable to do much biochemical work on suspensions of the organisms because of substantial loss of activity, usually over $90 \%$, on harvesting and resuspension. Various combinations of centrifugal force, time and variations in suspending solutions were tried; none resulted in a marked improvement in the activity of the recovered material. In general, centrifugation for longer times at lower values of $\boldsymbol{g}$ and with suspending solutions similar to the growth medium gave higher recoveries. However, one batch of the Jensen strain retained more activity than usual after harvesting and this was used to determine the Michaelis constants for ammonia- $\mathrm{N}$ and for oxygen by the polarographic method of Painter \& Jones (1963). The value for ammonia was found to be about I $\mathrm{mg}$. N/1. and for dissolved oxygen about $0.3 \mathrm{mg}$. $/ \mathrm{l}$. 
at $20^{\circ}$. These values agree well with those found for nitrification in the activatedsludge process (Department of Scientific and Industrial Research, 1963) and fairly well with the findings of Knowles et al. (1965) for Thames water.

\section{DISCUSSION}

With the technique described, little difficulty was encountered in the isolation of pure cultures of Nitrosomonas, which were active in the oxidation of ammonia. Contamination by heterotrophs was decreased by including only a little organic matter (in the form of chelated iron) in the medium and following the exponential accumulation of nitrite to a fairly high value before attempting dilutions for isolation. The addition of yeast extract to the isolation medium did not appear to impair seriously the growth of Nitrosomonas and caused heterotrophs to be readily apparent after 2-3 days of incubation. Repeated efforts to grow colonies on plates prepared with Difco Noble agar, as recommended by Engel \& Alexander (1958), were unsuccessful.

A potential deficiency in media usually employed was implicit in the work of Nicholas et al. (1962), which indicated that copper was an essential trace metal involved in an oxidase system of Nitrosomonas. This has been further confirmed by the present work, which shows that media prepared with analytical grade chemicals and high-quality water can be deficient in copper. There appears to be little doubt, in contrast to the statement of Engel \& Alexander (1958), that sodium is also a necessary trace metal since it was not difficult to demonstrate sodium deficiency in media prepared without added sodium. Added magnesium was found to stimulate growth, contrary to the findings of Skinner \& Walker (I96I) under comparable conditions. Recently, Khare, Chauhan \& Tandon (I966) have implicated zirconium, cerium, indium, thallium and beryllium in the nutrition of Nitrosomonas, but examination of the data presented shows that although the addition of these elements increased the final concentration of nitrite, the rate of production of nitrite was little affected.

The increase in growth when EDTA was added to the medium without added copper could be explained if the basal medium contained adequate copper, provided that some unidentified toxic metal which competitively interfered with copper nutrition was inactivated by chelation. (Postgate \& Hunter, 1962, found as much as $0.012 \mathrm{mg}$. $\mathrm{Cu} / 1$. in de-ionized water and Dixon \& Webb, 1958, listed metals between which competition exists for sites on enzymes.) On the other hand, the decreased growth resulting when EDTA was added without added calcium can be explained by assuming that this element is essential, but was present in the medium in such concentration that on chelation the free concentration of the element remaining was so low as to limit growth. The stimulation of growth usually observed on addition of EDTA to media containing added trace elements might be due to the co-operation or partition effects described by Albert (1965).

That further deficiencies or inhibitions existed was shown by the variations (Table 4) in mean generation times obtained in the complete medium and the repeated failure to reproduce the results of the experiment in which a concentration of $2500 \mathrm{mg}$. nitrite-N/1. and $96 \mathrm{mg}$. organic $\mathrm{C} / \mathrm{l}$. was reached, which are the highest values so far recorded in the literature. These variations and failures occurred in spite of the addition of what were regarded as the optimum concentrations of sodium, magnesium, calcium and copper. Figure I gives typical curves showing changes in the growth rate at around 
20-200 mg.N/1. Skinner \& Walker (I96I) recorded somewhat similar changes in growth rate but they took place at higher concentrations (I000 mg. N/1.).

The limitation of growth at $2500 \mathrm{mg}$. nitrite-N/1. was not due to lack of dissolved oxygen since the concentration of the gas was always over $2 \mathrm{mg}$./l., a value well above the Michaelis constant. It is possible, however, that inhibition was caused by the combined effect of $2500 \mathrm{mg}$. nitrite-N/1. and an approximately equal concentration of ammonia-N, added to neutralize the acidity formed. Lewis (1959) reported that 2500 mg. nitrite-N/1. was completely toxic in the logarithmic phase, although Pokallus (I963) found only 50\% inhibition at this concentration.

It is relevant to note the difficulty that various workers have experienced in trying to maintain their cultures in a viable state for long periods. Gundersen (I957) mentioned that Nitrosomonas seemed to be more frail than most other bacteria and Kingma Boltjes (1935) kept his cultures on agar slants enriched with a preparation of egg albumin. This specific preparation is no longer available and there are no reports of similar preparations having stimulatory effects; he apparently lost his cultures during the war, but no reason has been given. Meiklejohn (1950) lost all her cultures after about 18 months storage under various conditions, and Gundersen (I957) lost all his after $12-25$ months, again under a variety of conditions. The strain isolated by Jensen (1950) has also died out, although it must have survived in the hands of various workers for some 13 years. The activated-sludge strain used for the current work survived on various media for over 18 months and was then still as active as at the beginning. It is, however, quite certain that the strain would have been lost on several occasions if large numbers of parallel cultures had not been maintained under a variety of conditions, since during this period growth did fail several times. One reasonable interpretation of these experiences is that they are brought about by inadequate control of trace elements and more consistent results are likely to be achieved with a medium more carefully balanced with trace nutrients and buffered against toxic effects by the inclusion of adequate chelation capacity.

Many contradictions appear in the literature on the effect of $\mathrm{pH}$ value on respiration rate of Nitrosomonas and a variety of $\mathrm{pH}$ curves have been published. Typical of the extreme cases is that of Engel \& Alexander (1958), which is relatively flat between $\mathrm{pH} 7$ and 9, falling to about $50 \%$ at $6 \cdot 2$ and $9 \cdot 6$, and that of Meyerhof (1917), which has a sharp peak at $8 \cdot 6$, and $50 \%$ values at $7 \cdot 9$ and $9 \cdot 3$. In the present work similar extremes have been produced and appear to be due to the $\mathrm{pH}$ value strongly influencing the toxicity of copper and possibly other metals. The general picture may also be complicated by quantitative and possibly qualitative changes in the stimulatory effects of metals at different $\mathrm{pH}$ values, as has been shown for low concentrations of magnesium. Under the 'cleanest' conditions used in the present work $\mathrm{pH}$ value seemed to have little effect on growth over the $\mathrm{pH}$ range $7-8$; in all other cases the best $\mathrm{pH}$ value appeared to be in the range $7 \cdot 6-8 \cdot 0$.

The optimum temperature of the Nitrosomonas isolate was determined as $30^{\circ}$ and this is consistent with the findings of other workers. It is interesting to note, however, that the growth rate constant was substantially higher in pure culture and in Thames water than in activated sludge (Fig. 6). This may be due to an adverse environment in the activated-sludge system, e.g. toxic effects such as have been observed with peptone (Kingma Boltjes, I935; Buswell et al. 1954) or to slower-growing strains being selected in virtue of their flocculation. 


\section{REFERENCES}

Albert, A. (1965). Selective Toxicity, 3rd ed., p. 245. London: Methuen and Co. Ltd.

Bergey's Manual of Determinative Bacteriology. (1957). 7th ed. Ed. by R. S. Breed, E. G. D. Murray \& N. R. Smith. London: Baillière, Tindall and Cox Ltd.

BÖMEKE, H. (1946). Ưber die Ernährungs-und Wachstumsfaktoren der Nitrifikationsbakterien. Arch. Mikrobiol. 14, 63.

BRIGGS, R. \& VINEY, M. (1964). The design and performance of temperature compensated electrodes for oxygen measurement. J. scient. Instrum. 4r, 78.

Buswell, A. M., Shiota, T., Lawrence, N. \& Van Meter, I. (I954). Laboratory studies on the kinetics of the growth of Nitrosomonas with relation to the nitrification phase of the BOD test. Appl. Microbiol. 2, 2 I.

Callow, D. S. \& PIRT, S. J. (1956). Automatic control of $\mathrm{pH}$ value in cultures of micro-organisms. J. gen. Microbiol. 14, 66I.

Department of Scientific and Industrial Research (1963). Water Pollution Research 1962. London: H.M. Stationery Office.

Dixon, M. \& WeBb, E. C. (1958). Enzymes, 2nd ed. London: Longman and Co. Ltd.

Downing, A. L., Painter, H. A. \& Knowles, G. (1964). Nitrification in the activated-sludge process. J. Proc. Inst. Sew. Purif. p. 130.

EnGel, H. (1930). Die Oxydationsleistung der Einzelzelle von Nitrosomonas europaea. Arch. Mikrobiol. $\mathbf{1}, 445$.

ENGel, M.S. \& AleXander, M. (1958). Growth and autotrophic metabolism of Nitrosomonas europaea. J. Bact. 76, 217.

Gundersen, K. (1957). Preservation of Nitrosomonas. Nature, Lond. 179, 789.

JENSEN, H. L. (1950). Effect of organic compounds on Nitrosomonas. Nature, Lond. 165, 974.

Khare, H. P., Chauhan, J.S. \& Tandon, S. P. (I966). The effect of some rare elements on the growth of nitrite-formers. Zentbl. Bakt. Parasitkde 2. Abt., 120, II7.

Kingma Boltjes, T. Y. (1935). Untersuchungen über die nitrifizierenden Bakterien. Arch. Mikrobiol. 6, 79 .

Knowles, G., Downing, A. L. \& Barrett, M. J. (1965). Determination of kinetic constants for nitrifying bacteria in mixed culture with the aid of a computer. J. gen. Microbiol. 38, 263.

LEES, H. (1952). The biochemistry of the nitrifying organisms. I. The ammonia oxidizing systems of Nitrosomonas. Biochem. J. 52, I 34 .

LEES, H. (1960). Energy metabolism in chemolithotropic bacteria. A. Rev. Microbiol. I4, 83.

LEwIS, R. F. (1959). Isolation and growth of Nitromonas europaea in pure culture. Dissertation, Rutgers State University, New Jersey.

Lewis, R. F. \& Pramer, D. (1958). Isolation of Nitrosomonas in pure culture. J. Bact. 76, 524.

MeIKLEJoHn, J. (I950). The isolation of Nitrosomonas europaea in pure culture. J. gen. Microbiol. 4, I 85 .

MeyerhoF, O. (I917). Untersuchungen über den Atmungsvorgang nitrifizierender Bakterien. IV. Die Atmung des Nitritbildners und ihre Beeinflussung durch chemische Substanzen. Pflüg. Arch. ges. Physiol. 166, 240.

Montgomery, H. A. C. \& Dymock, J. F. (I96I). The determination of nitrite in water. Analyst, Lond. 86, 414 .

Nicholas, D. R. D., Wilson, P. W., Heinen, W., Palmer, G. \& Beinerts, H. (I962). Use of electron paramagnetic resonance spectroscopy in investigations of functional metal components in microorganisms. Nature, Lond. 196, 433.

PAINTER, H. A. \& JonEs, K. (I963). The use of the wide-bore dropping-mercury electrode for the determination of rates of oxygen uptake and of oxidation of ammonia by micro-organisms. J. appl. Bact. 26, 47I.

PoKallus, R. S. (1963). Toxicity of nitrite to Nitrosomonas europaea. Doctoral thesis, Rutgers State University, New Jersey.

Postgate, J. R. \& Hunter, J. R. (1962). The survival of starved bacteria. J. gen. Microbiol. 29, 233. 
SKINNER, F. A. \& WALKER, N. (196I). Growth of Nitrosomonas in batch and continuous culture. Arch. Mikrobiol. 38, 339.

TAPLIN, I. (I962). Continuous chemical sterilisation of media with $\beta$-propiolactone. Biotechnol. Bioengng 4, $33 \mathrm{I}$.

VAN Niel, C. B. (1954). The chemoautotrophic and photosynthetic bacteria. A. Rev. Microbiol. 8, 105. 